\title{
Application Value of Vital Signs Telemetry System for 2019 Novel Coronavirus Disease Suspected Cases in Isolation Wards
}

\author{
Jisong Zhang \\ Cheng Han \\ Fan Yang \\ Shan $\mathrm{Xu}$ \\ Huihui Hu \\ Enguo Chen
}

Department of Pulmonary and Critical Care Medicine, Sir Run Run Shaw Hospital of Zhejiang University, Hangzhou 310016, People's Republic of China
This article was published in the following Dove Press journal: Infection and Drug Resistance

\begin{abstract}
Objective: A large number of isolation wards were built to screen suspected patients because of the outbreak of coronavirus disease 2019 (COVID-19). The particularity of the isolation wards would lead to more medical resource consumption and heavier hospital control tasks. Therefore, we adopted a vital signs telemetry system in the isolation wards to improve this situation.
\end{abstract}

Materials and Technologies: Twenty sets of vital signs telemetry system were installed in the east district of the isolation area and the wards were used as the telemetry system wards (TSWs). The wards in the west district were used as the routine wards (RW). The daily telephone questionnaire was used to collect the frequency and time of ward rounds by medical staff and lasted for one week.

Results: Within one-week survey, the average frequency of RW rounds was $3.00 \pm 1.00$ times per day, and the average time was $93.57 \pm 66.25 \mathrm{~min}$. The daily frequency of RW rounds was $0.428 \pm 0.394$ times per capita, and the time was $7.88 \pm 2.36 \mathrm{~min}$. There was a statistically significant difference in the time of ward rounds per capita, which presented that the daily time of TSW rounds per capita was shorter than that of RW rounds. No security events related to telemetry equipment were found throughout the study.

Conclusion: The application of vital signs telemetry system as an alternative to traditional ward monitoring is considered feasible. The use of telemetry system can significantly reduce the consumption of medical resources, the workload of medical staff along with the administration and labor cost for isolation wards. The telemetry system provides sensitive and reliable real-time monitoring for the key indicators used for disease judgment and can make an accurate warning of the patients with disease aggravation in time. Thus, it is worthy of promotion and wide application.

Keywords: vital signs telemetry system, oxygen saturation, $\mathrm{SpO}_{2}$, coronavirus disease 2019, COVID-19, cross infection, nosocomial infection

\section{Background}

In December 2019, the outbreak of coronavirus disease 2019 (COVID-19) in Wuhan quickly spread to the whole country. Epidemic prevention and control became the top priority. COVID-19 is mainly transmitted by respiratory droplets and close contact, with high infectious and a propagation coefficient of $2.2,{ }^{1}$ which presents a great challenge to the control of nosocomial cross-infection and medical personnel's infection. China has implemented centralized diagnosis and unified management of confirmed cases. Isolation wards were set up for suspected cases for on-site isolation and
Department of Pulmonary and Critical Care Medicine, Sir Run Run Shaw Hospital of Zhejiang University, No. 3 East Qingchun Road, Jianggan District, Hangzhou 310016, People's Republic of China

Tel +86 I3588706779

Email 3195024@zju.edu.cn
Infection and Drug Resistance 2020:13 297|-2977

2971 
treatment. In order to improve the use efficiency of medical materials and reduce the risk of nosocomial infection, we adopted the new vital signs telemetry system in isolation wards for COVID-19 screening in Sir Run Run Shaw Hospital affiliated to Zhejiang University School of Medicine and reported the application situation.

\section{Materials and Technologies}

A total of 20 sets of vital signs telemetry system were installed in 20 isolation wards in Sir Run Run Shaw
Hospital affiliated to Zhejiang University School of Medicine. Each ward has only one bed and is equipped with one set of vital signs telemetry system. This system belongs to non-implanted noninvasive telemetry system consisting of ring-type medical pulse oximeter, noncontact radar respiratory monitor and remote vital signs telemetry platform (Figure 1) (the system is designed by College of Biomedical Engineering and Instrument Science in Zhejiang University, Sir Run Run Shaw Hospital affiliated to Zhejiang University School of Medicine and

A

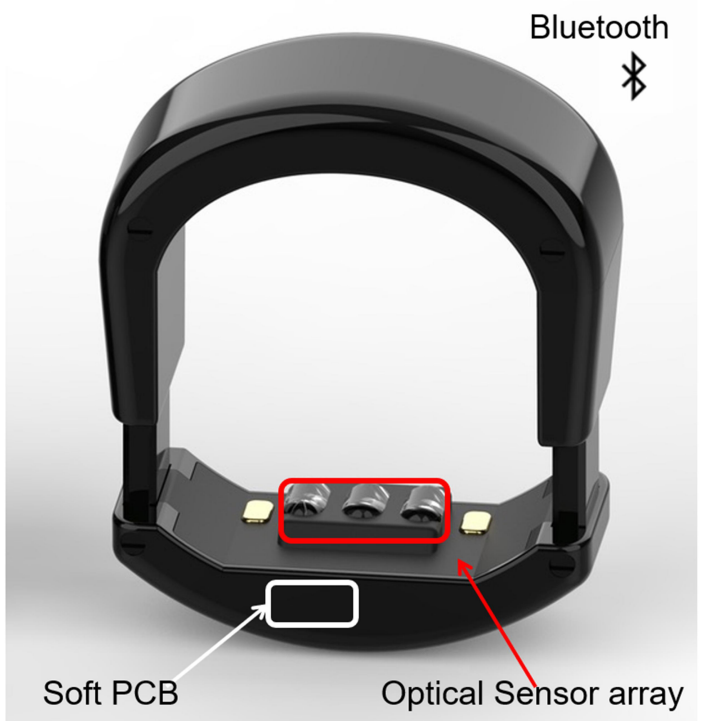

Medical wireless Pulse oximeter

B

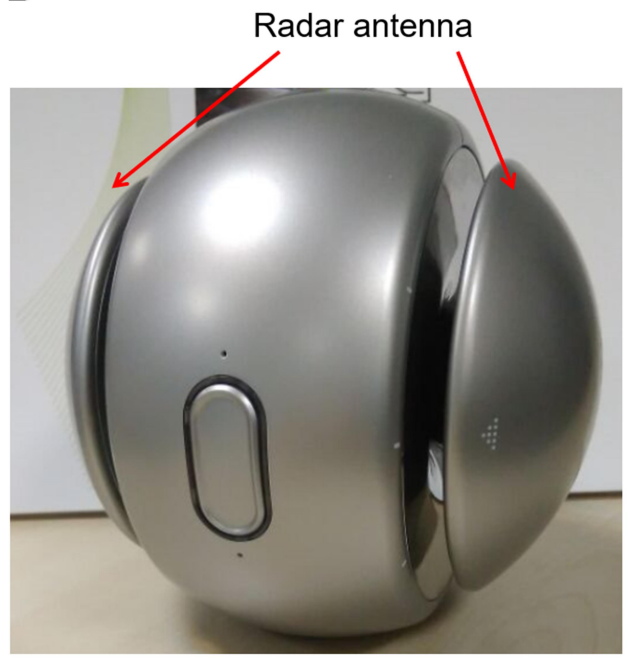

UWB Monitor Radar

Megahealth Ring is an innovative wearable continuous pulse oximeter, which has been certified to CFDA Class II for medical devices and hospitalized for clinical use. It measures PR and SPO2 precisely at the abdomen of the finger. The ring can be used for daily health monitoring and screening for diseases such as COPD and SAHS. The interface and inner arch are ergonomically shaped and the retractable sensor design is ingenious. It has not only the toughness and stability of stainless steel(inner shell), but also the wear resistance and moisture resistance of PVD(outer shell). The patented sensor structure embedded in the ring contains three types of wavelength sources: R, G and IR. The ring is produced with a fully potting process and has a waterproof grade of IP68.

MegaHealth UWB Radar Sleep Monitoring System has obtained the registration certificate for medical devices issued by CFDA.

With UWB bio-radar monitoring technology, the device can detect thoracoabdominal movement caused by breath, get such information as breath and movement of the whole body through radar echo, and thus uninterruptedly monitor sleep apnea.

No contact, anti-interference, maintenance-free and good reliability.

Flexible and adjustable device distance.1/400 of bluetooth transmitting power, safety and radiation-free.

Figure I (A) Non-contact radar respiratory monitor. (B) Ring type medical pulse oximeter 
Hangzhou MegaHealth sensing technology Co., LTD, and has been used in sleep monitoring wards in our hospital for 2 years). The ring pulse oximeter was used to calculate the blood oxygen saturation $\left(\mathrm{SpO}_{2}\right)$ of the patients by collecting the attenuated signal sent by built-in photodiode through the finger. It is convenient to wear and not easy to fall off with the shape similar to the ordinary ring. The non-contact radar respiratory monitor was placed within one meter of patients to collect the respiratory information by using the bio-radar sensor technology. The main data collected were heart rate, $\mathrm{SpO}_{2}$ and respiratory rate. The monitoring data were uploaded to the telemetry center in real-time via Bluetooth to realize the real-time alarm prompt of abnormal value (Figure 2).

Outpatients in our hospital who $\mathrm{mt}$ the diagnostic criteria for isolated patients were admitted to the isolation wards to undergo further COVID-19 nucleic acid testing. If the patient is tested negative for nucleic acid twice in succession, COVID-19 is excluded, and the patient will be discharged or transferred to a general ward for further treatment based on the medical condition. If the patient's nucleic acid testing is positive, COVID-19 is suspected and the patient will be sent to the COVID-19 designated hospital for further treatment. The floor of the isolation wards in our hospital was divided into 2 districts, which were under the charge of different nurse teams, respectively. The east district was telemetry system ward (TSW) area with 20 wards, while the west district was routine ward (RW) area with 23 wards. The frequency of vital signs collection was in accordance with the nursing levels prescribed by the doctor in no special circumstances. Blood pressure and body temperature were taken quaque die (QD), and respiratory rate, heart rate and $\mathrm{SpO}_{2}$ were collected bis in die (Bid) for first-class nursing patients. Blood pressure and body temperature were collected Bid and respiratory rate, heart rate along with $\mathrm{SpO}_{2}$ were collected once every $2 \mathrm{~h}$ (Q2h) for intensive patients. The frequency and time of ward rounds in the TSW and the RW were recorded daily for one week. The researchers interviewed medical staff working in isolation wards (including TSW and RW) every day through telephone questionnaires to collect the frequency and time of ward rounds. The data were analyzed by SPSS 19.0 statistical analysis software and verified by independent $t$-test. $P<0.05$ was considered statistically significant.

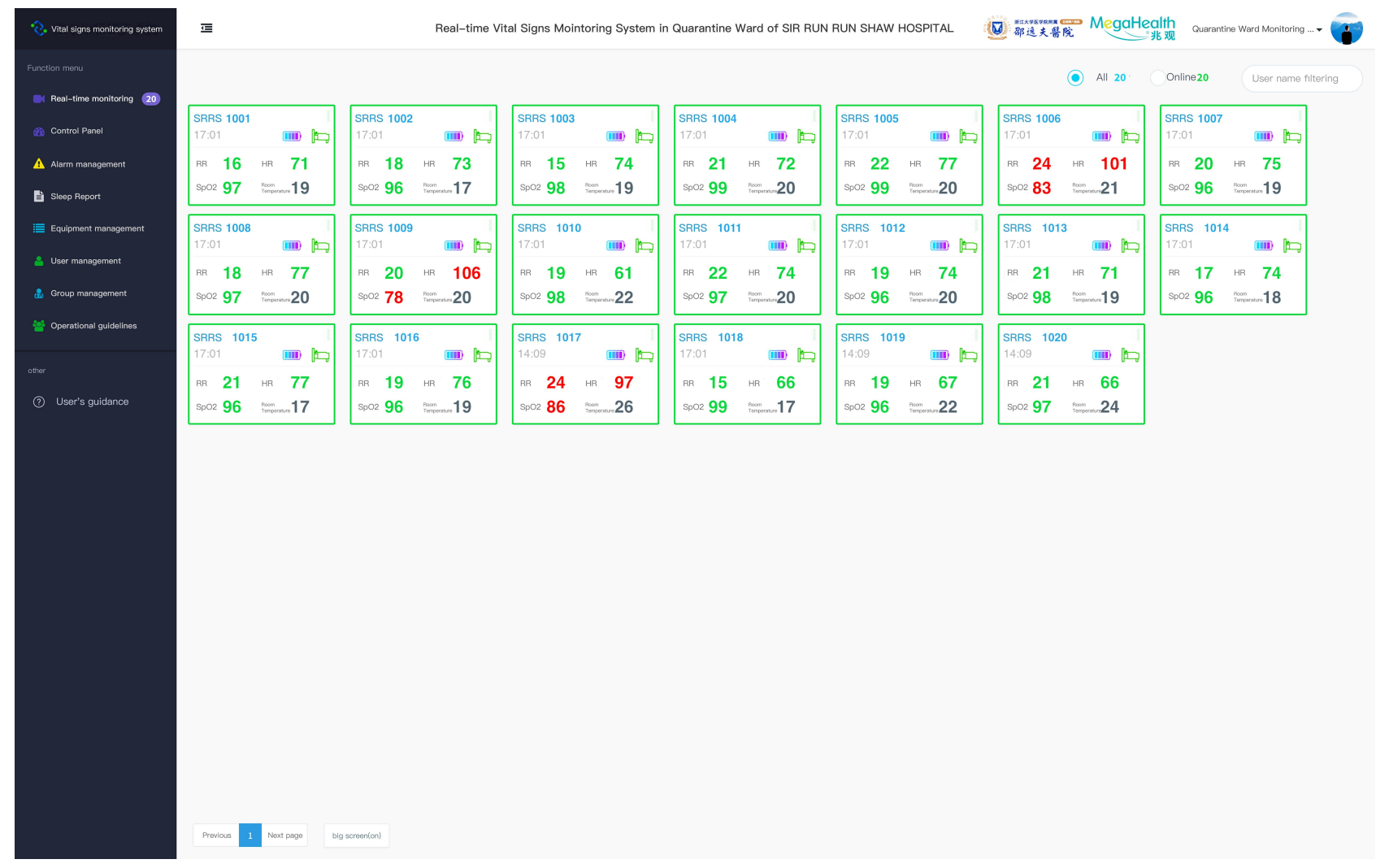

Figure 2 Monitor interface of vital signs telemetry system. 


\section{Results}

We calculated the frequency and time of ward rounds by medical staff from 2020.02.03 to 2020.02.09 for a total of 7 days (Table 1). During this period, a total of 63 suspected COVID-19 cases were included in our hospital, including 3 cases who were confirmed later. All the patients were suspected of COVID-19 without respiratory failure. Among them, 32 patients aged 15 to 68 years old were admitted to RW, with an average age of $38.77 \pm 14.03$ years old and the average hospitalization day of $1.90 \pm 0.30$ days. Thirty-one patients were in TSW aged 6 to 78 years old with an average age of $47.28 \pm 17.46$ years old and the average hospitalization day of $1.94 \pm 0.25$ days. For patients admitted to the two kinds of wards, the independent $t$-test showed that the $p$ value of age was 0.037 , indicating a statistical difference and the older overall age of patients in TSW. $P$ value of hospitalization day was 0.622 , indicating no statistical difference. No adverse medical events related to deterioration of the patient's condition and no instability of vital signs were found in TSW. No security events related to telemetry equipment were found throughout the study.

The average frequency of RW rounds was $3.00 \pm 1.00$ times per day, and the average time was $93.57 \pm 66.25 \mathrm{~min}$
(Mean $\pm \mathrm{SD}$ ). In addition, the average frequency of TSW rounds was $2.29 \pm 0.49$ times per day, and the average time was $81.43 \pm 40.69 \mathrm{~min}$ (Mean $\pm \mathrm{SD}$ ). Considering that the number of patients in the hospital would affect the frequency and time of daily ward rounds, so we counted the number of cases in the hospital every day, and calculated the daily frequency and time of ward rounds per capita, respectively. It was concluded that the daily frequency of RW rounds was $0.428 \pm 0.394$ times per capita, and the time was $7.88 \pm 2.36 \mathrm{~min}$ (Mean $\pm \mathrm{SD}$ ). While in the TSW, the daily frequency was $0.175 \pm 0.054$ times per capita, and the time was $5.59 \pm 0.91$ min (Mean \pm SD). Statistical results indicated that the daily frequency of ward rounds per capita was different in different types of wards, and that of TSW was lower than that of RW, but the difference was not statistically significant. However, there was a statistically significant difference in the time of ward rounds, which presented that the daily time of TSW per capita was shorter than that of RW.

\section{Discussion}

Telemetry has been used in animal ovarian experiments since the $1960 \mathrm{~s}^{2}$ With the development of technologies, the existing

Table I Frequency and Time of Ward Rounds by Medical Staff

\begin{tabular}{|c|c|c|c|c|c|c|}
\hline Date & & $\begin{array}{l}\text { One-Day Frequency of } \\
\text { Ward Rounds (Doctors } \\
\text { and Nurses) }\end{array}$ & $\begin{array}{l}\text { One-Day Time } \\
\text { of Ward Rounds } \\
\text { (min) }\end{array}$ & $\begin{array}{l}\text { Number of } \\
\text { Cases in the } \\
\text { Hospital }\end{array}$ & $\begin{array}{l}\text { Time of Ward } \\
\text { Rounds Per } \\
\text { Capita (min) }\end{array}$ & $\begin{array}{l}\text { Frequency of } \\
\text { Ward Rounds } \\
\text { Per Capita }\end{array}$ \\
\hline \multirow[t]{2}{*}{2.3} & TSW & 2 & 55 & 11 & 5 & 0.182 \\
\hline & RW & 3 & 80 & 17 & 4.71 & 0.176 \\
\hline \multirow[t]{2}{*}{2.4} & TSW & 2 & 70 & 14 & 5 & 0.143 \\
\hline & RW & 3 & 90 & 19 & 4.74 & 0.158 \\
\hline \multirow[t]{2}{*}{2.5} & TSW & 2 & 80 & 15 & 5.33 & 0.133 \\
\hline & RW & 5 & 210 & 27 & 7.78 & 0.185 \\
\hline \multirow[t]{2}{*}{2.6} & TSW & 3 & 145 & 23 & 6.3 & 0.13 \\
\hline & RW & 3 & 135 & 17 & 7.94 & 0.176 \\
\hline \multirow[t]{2}{*}{2.7} & TSW & 3 & 130 & 18 & 7.22 & 0.167 \\
\hline & RW & 3 & 100 & 10 & 10 & 0.3 \\
\hline \multirow[t]{2}{*}{2.8} & TSW & 2 & 50 & 11 & 4.55 & 0.182 \\
\hline & RW & 2 & 20 & 2 & 10 & I \\
\hline \multirow[t]{2}{*}{2.9} & TSW & 2 & 40 & 7 & 5.71 & 0.286 \\
\hline & RW & 2 & 20 & 2 & 10 & 1 \\
\hline Daily average value & TSW & 2.29 & 81.43 & NA & 5.59 & 0.175 \\
\hline \multirow[b]{2}{*}{$P$ value } & RW & 3 & 93.57 & NA & 7.88 & 0.428 \\
\hline & & & & & 0.034 & 0.118 \\
\hline
\end{tabular}

Abbreviations: TSW, telemetry system ward; RW, routine ward. 
telemetry technology has changed from invasive implanted technique to non-invasive one, and the detection of various vital signs is becoming more and more accurate. The monitoring range includes body temperature, blood pressure, pulse, heart rate, respiratory rate, electrocardiogram (ECG) and other vital information. A study involving 391 patients confirmed the reliability and safety of non-invasive telemetry system for monitoring patient's vital signs and ECG. ${ }^{3}$

The prevention and control of the COVID-19 have been successful in China, which can be summarized as isolation for suspected cases, mobile cabin hospital for mild cases, treatment for critical cases, and strict prevention of nosocomial infection. The control of nosocomial cross-infection, the reduction of the infection risk and the burden of medical staff are the focuses of prevention and control work at any stage. There were 3019 medical staff nationwide infected with COVID-19 up to February 18th, including 1716 confirmed cases and five deaths. ${ }^{4}$ The management of the isolation wards requires more refinement due to the particularity than that of the confirmed COVID-19 wards. Specific requirements consist of single private ward isolation, personal belongings for private use, regular replacement of protective suit for medical staff and ward round. Frequent replacement of protective suit and disinfection procedures not only cost medical supplies and time but also greatly increase the workload and the infection risk for medical staff. Meanwhile, we also need to find timely and treat the suspected cases with aggravating situation.

Through the vital signs telemetry system in isolation wards combined with the telephone questionnaire collecting related information (Figure 3), it was found that compared with RW, the vital signs telemetry system in TSW could significantly reduce the frequency and time of ward rounds. It reduced consumption of medical supplies, such as

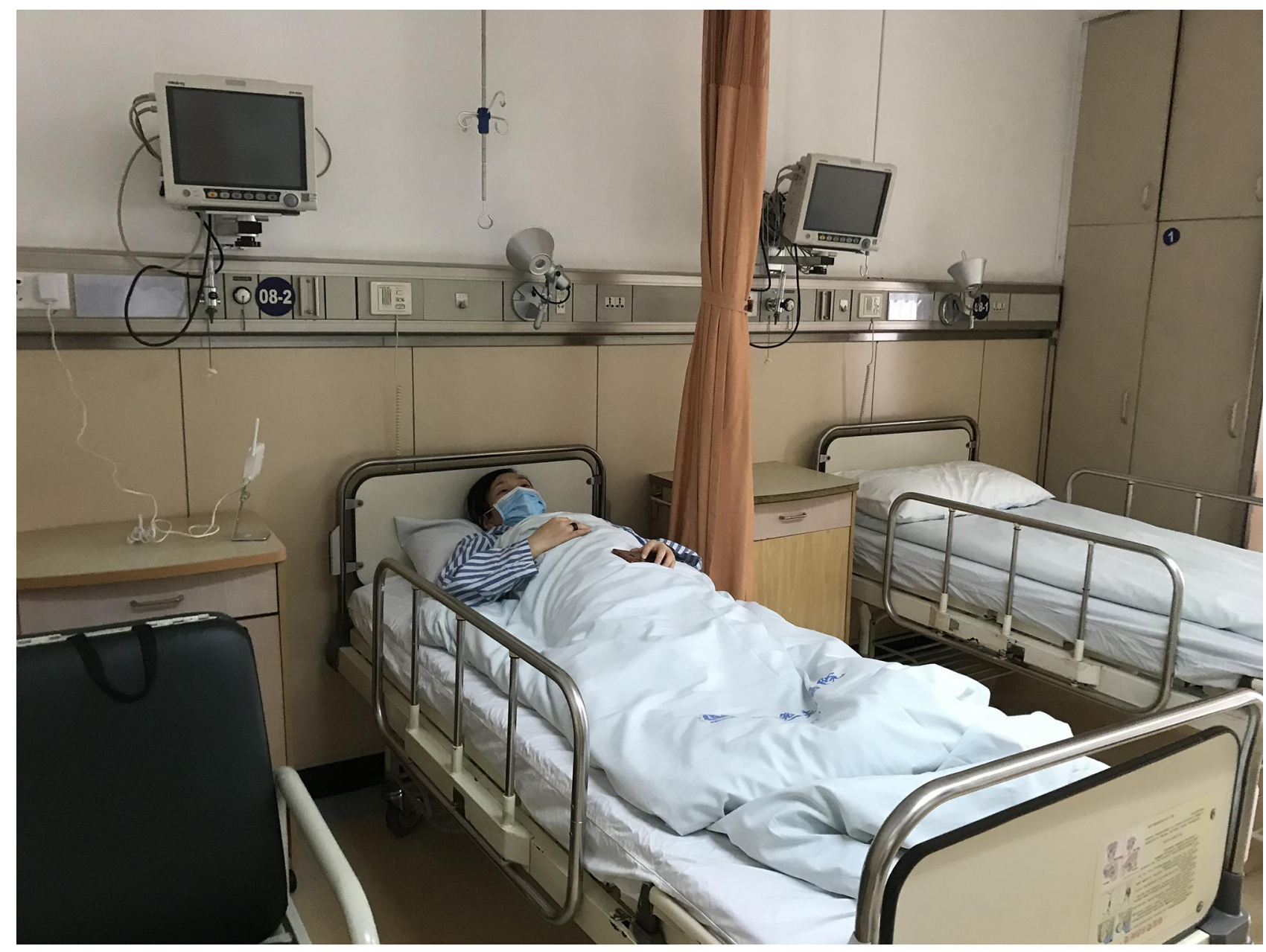

The patient is using telemetry system to monitor vital signs

Figure 3 The patient is being tested by the telemetry system for monitoring vital signs. 
isolation gown and protective suit, reduced the unnecessary contact between doctors and patients to a certain extent, and decreased the risk of nosocomial cross infection. At the same time, the application of this system also reduced the consumption of human resource and the management cost for the isolation wards. Compared with the traditional respiratory and $\mathrm{SpO}_{2}$ monitoring equipment, the vital signs telemetry system is convenient to deploy and non-invasive to monitor. The equipment can automatically upload monitoring data through the Internet and can display the realtime data by remote centralized monitoring center computer. It is appropriate to carry out continuous and real-time vital signs telemetry monitoring in COVID-19 and other highly infectious cases as well as suspected isolated cases, which is conducive to reducing the workload and the time of medical staff in the ward. Moreover, the system is conducive to data collation and output, and beneficial for the data information management. The deficiency of the system is that the monitored vital signs are not comprehensive, and further improvement can increase the monitoring of body temperature, blood pressure and other indicators, so as to improve the clinical practicability.

Another issue worthy of great attention is whether the telemetry system will cause inaccurate assessment of patients and corresponding medical risks. Several recent clinical studies have shown that typical clinical symptoms of COVID-19 include fever, shortness of breath, cough, headache, fatigue and so on. ${ }^{5}$ Among them, shortness of breath is a very important symptom closely related to the severity of patient's condition, and it also appears in the elderly ${ }^{6}$ and children. ${ }^{7}$ Most patients firstly show changes in $\mathrm{SpO}_{2}$ when their condition is exacerbated. Therefore, monitoring of $\mathrm{SpO}_{2}$ is vital for assessing the change and severity of patient's condition. When $\mathrm{SpO}_{2}$ drops below $93 \%$, or patient's breathing rate begins to accelerate, the patient's condition becomes worsening. ${ }^{5}$ Compared with conventional pneumonia, COVID-19 has a greater proportion of dyspnea and a higher breathing rate. ${ }^{8}$ The telemetry system can monitor these two indicators round the clock. On the one hand, COVID-19 patients can be screened as early as possible before the COVID-19 nucleic acid testing result coming out. On the other hand, the continuous monitoring and automatic early warning by the telemetry system also ensure the safety of patients. It is almost impossible to miss a patient with deteriorated condition.

Generally speaking, the vital signs telemetry system is safe and reliable, which has positive significance in reducing nosocomial infection risk, saving medical supplies, reducing the workload of medical staff and decreasing the management cost of isolation wards. It is especially suitable for the isolation wards of severe infectious diseases, the contagious wards and other special workplaces with a promotional value.

\section{Ethics Approval and Consent to Participate}

This study was conducted in accordance with the Helsinki Declaration II and was approved by the Institutional Review Boards of the Run Run Shaw Hospital of Zhejiang University. Written informed consent was obtained from individual or guardian participants.

\section{Acknowledgments}

The authors gratefully acknowledge the funding from the National Key R\&D Program of China (No.2017YF F0210803). The authors also gratefully acknowledge the contribution of the expert Yiyu Zhuang from the Nursing Department, Sir Run Run Shaw hospital of Zhejiang University.

\section{Author Contributions}

All authors made substantial contributions to conception and design, acquisition of data, or analysis and interpretation of data; took part in drafting the article or revising it critically for important intellectual content; agreed to submit to the current journal; gave final approval of the version to be published; and agree to be accountable for all aspects of the work.

\section{Funding}

This work was supported by the National Key R\&D Program of China (No. 2017YFF0210803).

\section{Disclosure}

The authors declare that they have no potential conflicts of interest for this work.

\section{References}

1. Li Q, Guan X, Wu P, et al. Early transmission dynamics in Wuhan, China, of novel coronavirus-infected pneumonia. $N$ Engl $J$ Med. 2020;382(13):1199-1207. doi:10.1056/NEJMoa2001316

2. Balin H, Busser JH, Hatke F, et al. Radio telemetry system for the study of ovarian physiology. I. instrumentation. Obstet Gynecol. 1964;24:198-207.

3. Marouf M, Vukomanovic G, Saranovac L, Bozic M. Multi-purpose ECG telemetry system. Biomed Eng Online. 2017;16(80). doi:10.1186/ s12938-017-0371-6 
4. Team NCPERE. The epidemiological characteristics of an outbreak of 2019 novel coronavirus diseases (COVID-19) in China. Zhonghua Liu Xing Bing Xue Za Zhi. 2020;41(2):145-151. doi:10.3760/cma.j. issn.0254-6450.2020.02.003

5. Deng Y, Liu W, Liu K, et al. Clinical characteristics of fatal and recovered cases of coronavirus disease 2019 (COVID-19) in Wuhan, China: a retrospective study. Chin Med J (Engl). 2020;133 (11):1261-1267. doi:10.1097/CM9.0000000000000824

6. Lian J, Jin X, Hao S, et al. Analysis of epidemiological and clinical features in older patients with corona virus disease 2019 (COVID-19) out of Wuhan. Clin Infect Dis. 2020;71(15):740-747. doi:10.1093/cid/ ciaa 242
7. Su L, Ma X, Yu H, et al. The different clinical characteristics of corona virus disease cases between children and their families in China - the character of children with COVID-19. Emerg Microbes Infect. 2020;9(1):707-713. doi:10.1080/22221751.2020.1744483

8. Zhao D, Yao F, Wang L, et al. A comparative study on the clinical features of COVID-19 pneumonia to other pneumonias. Clin Infect Dis. 2020. doi:10.1093/cid/ciaa247

\section{Publish your work in this journal}

Infection and Drug Resistance is an international, peer-reviewed openaccess journal that focuses on the optimal treatment of infection (bacterial, fungal and viral) and the development and institution of preventive strategies to minimize the development and spread of resistance. The journal is specifically concerned with the epidemiology of antibiotic resistance and the mechanisms of resistance development and diffusion in both hospitals and the community. The manuscript management system is completely online and includes a very quick and fair peerreview system, which is all easy to use. Visit http://www.dovepress.com/ testimonials.php to read real quotes from published authors. 